Article

\title{
Performance Assessment of Five Different Soil Moisture Sensors under Irrigated Field Conditions in Oklahoma
}

\author{
Sumon Datta ${ }^{1, * \mathbb{C}}$, Saleh Taghvaeian ${ }^{1}{ }^{\mathbb{C}}$, Tyson E. Ochsner ${ }^{2}$, Daniel Moriasi ${ }^{3}$, \\ Prasanna Gowda ${ }^{3}$ and Jean L. Steiner ${ }^{3}$ \\ 1 Department of Biosystems and Agricultural Engineering, Oklahoma State University, \\ Stillwater, OK 74078, USA; saleh.taghvaeian@okstate.edu \\ 2 Department of Plant and Soil Sciences, Oklahoma State University, Stillwater, OK 74078, USA; \\ tyson.ochsner@okstate.edu \\ 3 USDA-ARS Grazinglands Research Laboratory, El Reno, OK 73036, USA; daniel.moriasi@ars.usda.gov (D.M.); \\ prasanna.gowda@ars.usda.gov (P.G.); jean.steiner@ars.usda.gov (J.L.S.) \\ * Correspondence: sdatta@okstate.edu; Tel.: +1-701-730-4742
}

Received: 9 October 2018; Accepted: 2 November 2018; Published: 5 November 2018

\begin{abstract}
Meeting the ever-increasing global food, feed, and fiber demands while conserving the quantity and quality of limited agricultural water resources and maintaining the sustainability of irrigated agriculture requires optimizing irrigation management using advanced technologies such as soil moisture sensors. In this study, the performance of five different soil moisture sensors was evaluated for their accuracy in two irrigated cropping systems, one each in central and southwest Oklahoma, with variable levels of soil salinity and clay content. With factory calibrations, three of the sensors had sufficient accuracies at the site with lower levels of salinity and clay, while none of them performed satisfactorily at the site with higher levels of salinity and clay. The study also investigated the performance of different approaches (laboratory, sensor-based, and the Rosetta model) to determine soil moisture thresholds required for irrigation scheduling, i.e., field capacity (FC) and wilting point (WP). The estimated FC and WP by the Rosetta model were closest to the laboratory-measured data using undisturbed soil cores, regardless of the type and number of input parameters used in the Rosetta model. The sensor-based method of ranking the readings resulted in overestimation of FC and WP. Finally, soil moisture depletion, a critical parameter in effective irrigation scheduling, was calculated by combining sensor readings and FC estimates. Ranking-based FC resulted in overestimation of soil moisture depletion, even for accurate sensors at the site with lower levels of salinity and clay.
\end{abstract}

Keywords: volumetric water content; salinity; soil moisture depletion; irrigation management

\section{Introduction}

Irrigated agriculture, a major contributor to the United States (U.S.) economy, plays a vital role in supplying the demand for food, feed, and fiber. Although only $27 \%$ of all croplands in the U.S. are irrigated, this sector is responsible for nearly $50 \%$ of crop revenues [1]. Sustaining high levels of food production through irrigated agriculture requires large amounts of water. In 2010, irrigation was the second largest consumer of freshwater withdrawals in the U.S., accounting for approximately $33 \%$ (approximately 159 million $\mathrm{m}^{3}$ year ${ }^{-1}$ ) of the total water withdrawals [2]. Irrigation water sources, however, are usually limited in amount and are subject to increasing competition. In addition, more variability in precipitation patterns is expected due to climate change, which may threaten the availability of irrigation water supplies [3,4]. These challenges create the need to 
optimize irrigation management and avoid over- or under-irrigation. Over-irrigation, in addition to wasting water and valuable nutrients, can create favorable conditions for pests and diseases, increase energy costs, and reduce the lifespan of irrigation infrastructure. It can also result in erosion of topsoil and contamination of downstream water resources due to movement of water-soluble chemicals [5]. In contrast, under-irrigation reduces crop yield and negatively impacts economic viability of agricultural production.

Several advanced technologies are available to assist with achieving and implementing optimized irrigation management, including weather stations, air- and spaceborne remote sensing platforms, computer models, plant feedback sensors, and soil moisture sensors [6,7]. Soil moisture sensors, in particular, can be used effectively to improve irrigation management [8]. As a tool for irrigation scheduling, these sensors have been shown to increase crop yields while conserving water [8-11]. For example, Zotarelli et al. [12] showed that users who manage irrigation with soil moisture sensors applied 15 to $51 \%$ less irrigation water compared to fixed-time irrigation plan and observed a crop yield increase of 11 to $26 \%$ in Florida, U.S. In addition, sensors can provide continuous estimate of soil moisture conditions in a nondestructive way at a reasonable cost and usually require little maintenance over their lifetime [13]. Soil moisture sensors include tensiometers, neutron gauges, electromagnetic sensors, electrical resistance sensors, and heat dissipation sensors, to name a few [14]. Among these different types, electromagnetic sensors have been widely used by producers for irrigation scheduling.

Despite their numerous advantages, electromagnetic sensors are sensitive to soil salinity and clay content. The impact of soil salinity on sensor readings of soil volumetric water content $\left(\theta_{v}\right)$ $\left(\mathrm{m}^{3} \mathrm{~m}^{-3}\right)$ has been highlighted in several studies [15-17]. For example, Wyseure et al. [16] reported that $\theta_{v}$ error was acceptable at soil bulk electricity conductivity (EC) $\left(\mathrm{dS} \mathrm{m} \mathrm{m}^{-1}\right)$ levels below $2.0 \mathrm{dS} \mathrm{m}^{-1}$, and Schwartz et al. [18] found that $\theta_{v}$ estimates were not affected at bulk EC levels below $2.8 \mathrm{dS} \mathrm{m}^{-1}$. These thresholds are exceeded in many irrigated areas in arid/semi-arid regions, where there is a great need for improving irrigation management using sensor technologies. The results from prior studies on the impact of clay content have been somewhat variable. Rüdiger et al. [19] observed overestimation error in $\theta_{v}$ that increased with clay content. In contrast, Fares et al. [20] observed underestimation of $\theta_{v}$ for electromagnetic sensors due to high clay content, which was more prevalent at lower soil moisture content. Mittelbach, et al. [21] reported both under- and overestimation errors at different depths of a clay loam soil in Switzerland. In light of these variable results, and since high salinity and clay content conditions are encountered in many agricultural fields, there is a need to undertake further field studies to investigate the accuracy of electromagnetic soil moisture sensors under varying levels of salinity and clay content.

The goal of this study was to evaluate the performance of soil moisture sensors for irrigation scheduling purposes under low and high salinity/clay content conditions. Specific objectives were to (1) assess the performance of five different commercially available electromagnetic sensors in estimating $\theta_{v}$ in situ under soils with variable salt and clay content, (2) compare the accuracy of several approaches of determining soil moisture thresholds used in irrigation scheduling, and (3) investigate the accuracy of estimated soil moisture depletion based on sensor readings and different threshold approaches.

\section{Materials and Methods}

\subsection{Sensor Description}

Five commercially available electromagnetic sensors were evaluated in this study: TDR315, CS655, GS1, SM100, and CropX.

\subsubsection{TDR315}

The TDR315 (Acclima Inc., Meridian, ID, USA) is a recently commercialized sensor for agricultural applications [18]. This sensor operates on principles of Time Domain Reflectometry (TDR) that estimates the soil apparent permittivity $\left(K_{a}\right)$ (unitless) at relatively higher frequencies $(3.5 \mathrm{GHz})$, 
which are less sensitive to bulk EC compared to lower frequency electromagnetic techniques [22]. Conventional TDR sensors have a problem sustaining high frequency signals because of signal attenuation in the sensor's coaxial cables. The TDR315 addresses this issue by embedding all the electronics required for pulse generation and waveform acquisition in a compact circuit within the probe head. The data are transmitted digitally via SDI-12 (Serial Data Interface at 1200 baud) protocol, which is an asynchronous, ASCII, serial communications protocol and can support a cable length of up to $60 \mathrm{~m}$. The sensor shares the same advantages of the conventional TDRs, but, it is more portable, affordable, and convenient to use [18]. These sensors have a planar three-conductor transmission line, each $15 \mathrm{~cm}$ long, and transmit the incident pulse in the center rod and two exterior grounds. The TDR315 reports volumetric water content $\left(\theta_{v}\right)(\%)$ based on a proprietary dielectric mixed model which estimates $K_{a}$ using Topp equation (Equation (1)) [17]. The sensor also reports soil temperature $\left({ }^{\circ} \mathrm{C}\right)$, bulk relative permittivity (unitless), bulk EC $\left(\mu \mathrm{S} \mathrm{cm}{ }^{-1}\right)$, and soil pore water EC $\left(\mu \mathrm{S} \mathrm{cm}{ }^{-1}\right)$. DataSnap SDI-12 data-loggers from the same manufacturer were used with TDR315 sensors to collect data on hourly basis.

$$
\theta_{v}=4.3 \times 10^{-6} \times\left(K_{a}^{3}\right)-5.5 \times 10^{-4} \times\left(K_{a}^{2}\right)+2.92 \times 10^{-2} \times\left(K_{a}\right)-5.3 \times 10^{-2}
$$

\subsubsection{CS655}

The CS655 sensor (Campbell Scientific, Inc., Logan, UT, USA) is a water content reflectometer. An electronic pulse is sent from the probe head and reflected at the end of the rods $(12 \mathrm{~cm}$ in length). Upon detecting the returned pulse, another pulse is sent. Then, the probe records the frequency of these pulses and inverses the frequency as period in microseconds $(\mu \mathrm{s})$. This period is impacted by the velocity of electromagnetic pulse, which is influenced by $K_{a}[17,23]$. The probe estimates $\theta_{v}$ from $K_{a}$ using the Topp equation (Equation (1)) [17]. Apart from $\theta_{v}$, other measured parameters include period average ( $\mu \mathrm{s})$, soil's relative dielectric permittivity (unitless), bulk EC $\left(\mathrm{dS} \mathrm{m}^{-1}\right)$, and soil temperature $\left({ }^{\circ} \mathrm{C}\right)$. Like the TDR315, the CS655 communicates with a data-logger using an SDI-12 interface. To collect hourly data, CR1000 data-loggers (Campbell Scientific, Inc., Logan, UT, USA) were used in this study.

\subsubsection{GS1}

The GS1 sensor (METER Group, Inc., Pullman, WA, USA) estimates $\theta_{v}$ by generating an electromagnetic field to measure the dielectric constant of the surrounding medium. This sensor uses capacitance and frequency domain technology and operates at $70 \mathrm{MHz}$ [24]. It provides oscillating waves to the sensor rods that charge in response to the dielectric of the material. The sensor quantifies the charge and provides a raw value (RV) that is strongly correlated with $\theta_{v}$ (Equation (2)). The GS1 has a rugged design and is capable of remaining in the soil for a long time. It has a two-rod design, with each rod measuring $5.5 \mathrm{~cm}$ in length. Hourly data were collected throughout the cropping season using EM5B analog data-loggers (METER Group, Inc., Pullman, WA, USA).

$$
\theta_{v}=3.62 \times 10^{-4}(\mathrm{RV})-0.554
$$

\subsubsection{SM100}

The WaterScout SM100 sensor (Spectrum Technologies, Aurora, IL, USA) has two electrodes functioning as a capacitor, with surrounding soil acting as the dielectric. The capacitor is driven by an $80 \mathrm{MHz}$ oscillator and converts the soil's dielectric permittivity to an output signal, which correlates with $\theta_{v}$. Watchdog 1400 data-loggers from the same manufacturer were used to collect hourly data.

\subsubsection{CropX}

The CropX sensor (CropX Ltd., Tel Aviv, Israel) integrates soil moisture sensing and a cellular communication package. The sensor electrodes are built into a helical wing attached to a central shaft for installation with reduced soil disturbance. The sensor measures soil moisture based on the 
amplitude domain reflectometry. When the amount of water changes in the soil, the sensor measures the change in amplitude differential due to changes in dielectric permittivity, which directly correlates to changes in water content. CropX is a multiprobe sensor that measures $\theta_{v}$ at 20 and $46 \mathrm{~cm}$ depths in the soil.

\subsection{Study Sites}

The study took place during the 2017 crop growing season. Two sites were selected for sensor installation, one with lower salinity and lower clay content (LSLC) located in central Oklahoma and the other in southwest Oklahoma with higher salinity and higher clay content (HSHC). Figure 1 shows the location of the study sites overlaid on the map of long-term mean annual precipitation across Oklahoma, obtained from Daly et al. [25]. The LSLC site had a Pond Creek fine sandy loam soil (fine-silty, mixed, superactive, thermic Pachic Argiustolls) while the HSHC site had a Hollister silty clay loam soil (fine, smectitic, thermic Typic Haplusterts). The EC of the soil solution (1:1 soil-water ratio) was $1.2 \mathrm{dS} \mathrm{m}^{-1}$ at LSLC compared to $7.0 \mathrm{dS} \mathrm{m}^{-1}$ at HSHC. Table 1 provides additional information on soil characteristics at each site. In addition to variations in soils, the two sites were different in crop types, irrigation systems, and climatic conditions. Corn (Zea mays L.) was planted at the LSLC site under a center-pivot irrigation system, while the HSHC site was under furrow-irrigated cotton (Gossypium hirsutum L.). Key meteorological parameters for each site are given in Table 2.

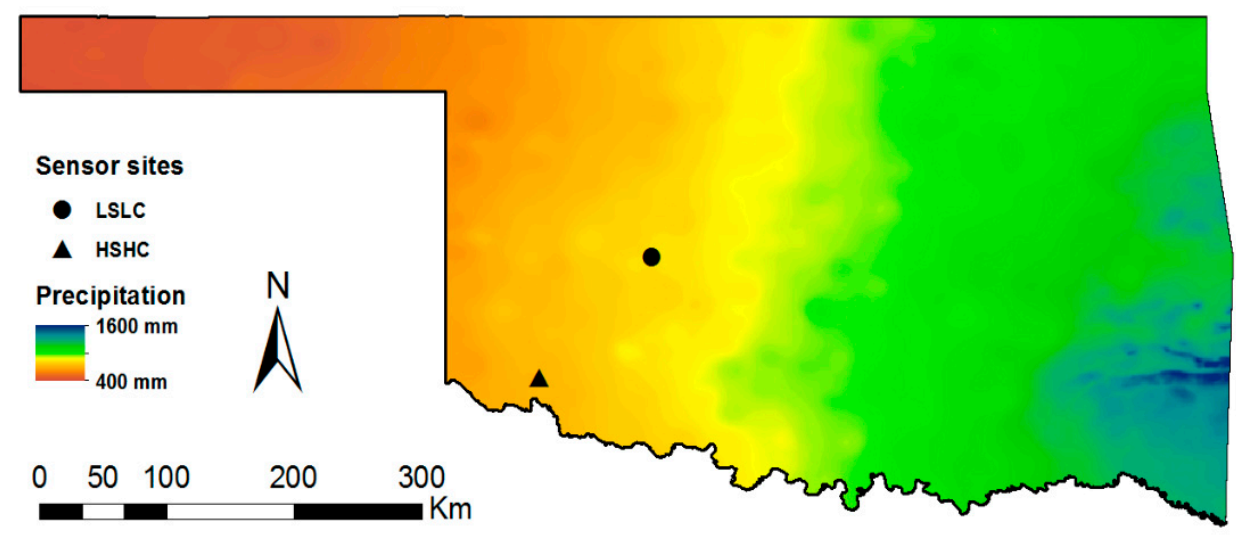

Figure 1. Experimental study site locations.

Table 1. Soil properties at study sites.

\begin{tabular}{|c|c|c|c|c|c|c|c|c|c|}
\hline \multirow{2}{*}{ Site } & \multirow{2}{*}{ Soil Texture } & \multicolumn{3}{|c|}{ Particle Size Distribution } & \multirow{2}{*}{$\frac{E C^{¥}}{\left(\mathrm{dS} \mathrm{m}^{-1}\right)}$} & \multicolumn{3}{|c|}{$\theta_{v}\left(\mathrm{~m}^{3} \mathrm{~m}^{-3}\right)$} & \multirow{2}{*}{$\frac{\mathrm{K}_{\mathrm{sat}}{ }^{\dagger}}{\left(\mathrm{mm} \mathrm{day}^{-1}\right)}$} \\
\hline & & $\%$ Sand & $\%$ Silt & $\%$ Clay & & Sat. $\ddagger$ & FC $\$$ & $\mathrm{WP}^{*}$ & \\
\hline LSLC & Fine sandy loam & 72.2 & 14.4 & 13.4 & 1.2 & 0.34 & 0.17 & 0.05 & 390.0 \\
\hline $\mathrm{HSHC}$ & Silty clay loam & 23.5 & 37.8 & 38.7 & 7.0 & 0.39 & 0.32 & 0.21 & 32.4 \\
\hline
\end{tabular}

${ }^{¥}$ Electrical conductivity. ${ }^{\ddagger}$ Saturation level; ${ }^{\S}$ Field capacity at $-33 \mathrm{kPa} ;{ }^{*}$ Wilting point at $-1500 \mathrm{kPa} ;{ }^{\dagger}$ Saturated hydraulic conductivity. 
Table 2. Twenty-year (1997-2016) average annual and study period (July to October 2017) meteorological parameters obtained from Oklahoma Mesonet weather network.

\begin{tabular}{ccccc}
\hline \multirow{2}{*}{ Parameter } & \multicolumn{2}{c}{ Annual } & \multicolumn{2}{c}{ Study Period } \\
\cline { 2 - 5 } & LSLC & HSHC & LSLC & HSHC \\
\hline Total Prec. $^{1}(\mathrm{~mm})$ & 752 & 616 & 451 & 340 \\
${\text { Mean } \mathrm{R}_{\mathrm{s}}{ }^{2}\left(\mathrm{MJ} \mathrm{m}^{-2}\right)}{ }^{3}(7.1$ & 17.7 & 19.9 & 21.8 \\
Minimum $\left._{\text {air }}{ }^{\circ} \mathrm{C}\right)$ & 9.4 & 10.0 & 18.1 & 18.9 \\
Maximum $_{\text {air }}\left({ }^{\circ} \mathrm{C}\right)$ & 22.1 & 24.1 & 30.6 & 31.2 \\
${\text { Mean } \mathrm{T}_{\text {air }}\left({ }^{\circ} \mathrm{C}\right)}^{4}$ & 15.4 & 16.8 & 23.9 & 24.8 \\
Minimum RH $^{4}(\%)$ & 41.9 & 37.6 & 45.5 & 44.7 \\
Mean VPD $^{5}(\mathrm{kPa})$ & 0.9 & 1.0 & 1.0 & 1.1 \\
${\text { Mean } \mathrm{U}_{2}}^{6}\left(\mathrm{~m} \mathrm{~s}^{-1}\right)$ & 2.5 & 2.5 & 3.0 & 2.5 \\
\hline
\end{tabular}

${ }^{1}$ Precipitation; ${ }^{2}$ Daily accumulation of solar radiation; ${ }^{3}$ Daily air temperature; ${ }^{4}$ Daily relative humidity. ${ }^{5}$ Daily vapor pressure deficit; ${ }^{6}$ Daily wind speed at $2.0 \mathrm{~m}$ above the ground.

\subsection{Experimental Setup}

Four replications of TDR315, CS655, GS1, and SM100 and two replications of CropX were installed on 7/20/2017 and 7/27/2017 at LSLC and HSHC sites, respectively. The sensors were used with manufacturer-provided data-loggers and calibrations because the results obtained in this manner would best represent the conditions that irrigators and farm managers would face in the field [26]. Therefore, the raw $\theta_{v}$ readings reported by the sensors were used in analysis without any alteration [13]. It should be noted that developing and utilizing site-specific calibrations can significantly improve accuracies if the required technical and financial resources are available to users. All sensors were installed at a depth of $20 \mathrm{~cm}$ from the soil surface. The top $20 \mathrm{~cm}$ is important for plant water uptake as root distribution of plants is denser in this layer than deeper in the soil profile [27].

At each replication, a pit was dug between two rows of crops to install the soil moisture sensors. Physical properties of soil in each pit were determined in the Soil Physics Laboratory at Oklahoma State University (OSU) by taking undisturbed soil cores (diameter $=2.5 \mathrm{~cm}$, length $=5.1 \mathrm{~cm}$ ) using the Sample Ring Kit (Model C, Eijkelkamp Soil \& Water, Inc., Giesbeek, The Netherlands) on the day of sensor installation. Soil textural information (particle size distribution) were determined by hydrometer following the protocol proposed by Ashworth, et al. [28]. Additionally, four replications of soil samples were taken at each site on the installation day to measure soil salinity. The salinity test was done by Soil, Water and Forage Analytical Laboratory at OSU using the 1:1 soil water extraction method [29].

Sensors were inserted horizontally into the side wall of the pit (undisturbed soil) so that the rods of the sensors were on top of each other (vertical orientation) and the middle point of the sensor rods was directly under the crop row. The $\theta_{v}$ readings are often impacted by the sensor installation procedure [30], so extra care was taken to maintain minimal disturbance to the surrounding soil while inserting the rods. The spacing between the sensors was determined based on the volume of influence of individual sensors plus an additional distance to eliminate any possible interference. This spacing between the sensors were varied from 10 to $18 \mathrm{~cm}$ depending on the volume of influence of sensors' electromagnetic field. Then, wires were run below and away from the sensors for some distance to avoid creating any preferential flow channels. After that, the wires were run through PVC pipes to the data-logger encasement. The CropX sensors were installed using the spiral auger provided by the manufacturer to minimize soil disturbance.

The excavated soil was collected in different buckets for different soil layers and carefully used to backfill the pits, attempting to recreate the original bulk density. Precipitation amounts were recorded by a tipping bucket rain gage (model TE525-L, Campbell Scientific, Inc., Logan, UT, USA) at the LSLC site, whereas, these measurements were collected from an Oklahoma Mesonet weather station located $678 \mathrm{~m}$ to the southwest of the sensor installation location at the HSHC site [31]. Gravimetric soil samples (diameter $=3 \mathrm{~cm}$, height $=5.1 \mathrm{~cm}$ ) were collected using a Giddings soil sampling probe (Giddings Machine Company, Windsor, CO, USA) to estimate reference $\theta_{v}\left(\theta_{\text {ref }}\right)\left(\mathrm{m}^{3} \mathrm{~m}^{-3}\right)$ throughout 
the crop growing season. On each sampling date, four gravimetric samples were taken at each site and the probe was centered at the sensor installation depth $(20 \mathrm{~cm})$. If there was an irrigation and/or precipitation event around the sampling dates, extra care was taken not to compact the areas above the sensors. Soil samples were put in plastic bags immediately after sample collection and kept out of sunlight to minimize evaporation. All soil samples of known volumes were oven-dried at $105^{\circ} \mathrm{C}$ for $24 \mathrm{~h}$ and used to determine bulk density.

\subsection{Soil Moisture Thresholds}

Efficient irrigation management requires knowledge of two important soil moisture thresholds that indicate water availability for plant consumption [5]. These thresholds are field capacity (FC) and wilting point (WP). The FC is often estimated as the water retained at a soil matric potential of $-33 \mathrm{kPa}$, although research has shown that this can result in underestimation of FC and $-10 \mathrm{kPa}$ may provide a more suitable approximation [32]. The WP is often estimated as the water retained at $-1500 \mathrm{kPa}$ [33]. These values can be different depending on soil texture, crop type, and other factors.

In this study, FC and WP were determined using three different approaches: laboratory, sensor-based, and the Rosetta model [34]. Undisturbed soil cores extracted from each site were used in laboratory tests where FC was determined at $-33 \mathrm{kPa}$ using the Tempe cell method and WP at $-1500 \mathrm{kPa}$ using the pressure plate method [35]. The sensor-based approach was based on ranking of the collected data following the procedure proposed in Hunt et al. [36]. This method uses sensor readings to estimate $\mathrm{FC}$ and $\mathrm{WP}$ as the 95 th and the 5 th percentiles of all $\theta_{v}$ values collected during the study period. This method assumes that the hydrologic conditions during the measurement period result in $\theta_{v}$ values, which span from values lower than WP to values higher than FC. The Rosetta model uses hierarchical pedotransfer functions to estimate van Genuchten water retention parameters [34]. In this study, three different FC-WP outputs were generated from the Rosetta model by providing different types and combination of input data. The three types of input data included (i) only the textural class of soils at study sites, (ii) textural information (percentages of sand, silt, and clay), and, (iii) textural information and bulk density. Estimated FC and WP from all methods described above were compared with those reported in the U.S. Department of Agriculture's Web Soil Survey at each study site [37]. In addition to FC and WP, the available water content (AWC), which is the difference between FC and WP, was calculated and compared with values obtained from different methods described above [38].

To optimize irrigation management based on soil moisture sensing, sensor readings must be converted to soil moisture depletion (SMD) $\left(\mathrm{m}^{3} \mathrm{~m}^{-3}\right)$. In this study, SMD was calculated as the difference between FC and $\theta_{v}$ :

$$
S M D_{(i)}=\theta_{F C}-\theta_{v(i)}
$$

where, $S M D_{(i)}$ is the soil moisture depletion at the ith time-step, $\theta_{F C}$ is the $\theta_{v}$ at FC (constant) $\left(\mathrm{m}^{3} \mathrm{~m}^{-3}\right)$, and $\theta_{v(i)}$ is the $\theta_{v}$ at the $i$ th time-step. In estimating SMD, $\theta_{v(i)}$ values were obtained from sensor readings and $\theta_{F C}$ values were based on two different approaches, resulting in two SMD estimates for each sensor at each site. The two $\theta_{F C}$ approaches were the laboratory and the ranking methods explained above. The results were compared against SMD estimates based on $\theta_{\text {ref }}$ (gravimetric measurements) and laboratory $\theta_{F C}$. After SMD is estimated, it can be multiplied by the root zone depth to obtain an estimate of irrigation requirement in units of water depth.

\subsection{Statistical Analysis}

To evaluate the performance of the selected sensors, $\theta_{v}$ readings of sensors were compared with $\theta_{\text {ref }}$ values. Four statistical parameters, namely root mean square error (RMSE), RMSE-observations 
standard deviation ratio (RSR), mean bias error (MBE), and index of agreement ( $k$ ) were estimated according to the following equations.

$$
\begin{aligned}
& \mathrm{RMSE}=\sqrt{\frac{1}{n} \sum_{i=1}^{n}\left(P_{i}-O_{i}\right)^{2}} \\
& \mathrm{RSR}=\frac{\operatorname{RMSE}}{\operatorname{STDEV}_{O_{(i)}}}=\frac{\sqrt{\sum_{i=1}^{n}\left(O_{i}-P_{i}\right)^{2}}}{\sqrt{\sum_{i=1}^{n}\left(O_{i}-\bar{O}\right)^{2}}} \\
& \mathrm{MBE}=\frac{1}{n} \sum_{i=1}^{n}\left(P_{i}-O_{i}\right) \\
& k=1-\left[\frac{\sum_{i=1}^{n}\left(P_{i}-O_{i}\right)^{2}}{\sum_{i=1}^{n}\left(\left|P_{i}-\bar{O}\right|+\left|O_{i}-\bar{O}\right|\right)^{2}}\right]
\end{aligned}
$$

where, $n$ is the sample size, $i$ is the index of sample pairs, $P$ is the sensor reading (predicted), $O$ is the $\theta_{\text {ref }}$ (observed), and $\bar{O}$ is the mean of all $\theta_{\text {ref }}$ values.

The accuracy categories outlined in Fares et al. [20] were adopted in this study for interpreting RMSE values. These categories include good (RMSE $\left.\leq 0.01 \mathrm{~m}^{3} \mathrm{~m}^{-3}\right)$, fair $\left(0.01 \leq \mathrm{RMSE} \leq 0.05 \mathrm{~m}^{3} \mathrm{~m}^{-3}\right.$ ), poor $\left(0.05 \leq\right.$ RMSE $\left.\leq 0.10 \mathrm{~m}^{3} \mathrm{~m}^{-3}\right)$, and very poor (RMSE $\geq 0.10 \mathrm{~m}^{3} \mathrm{~m}^{-3}$ ). The RSR provides benefits of incorporating error index statistics and it includes a normalization factor applicable to various constituents [39]. The RSR varies from a value of zero indicating zero RMSE and a perfect model simulation to a large positive value. The performance of a model is determined by different categories of RSR: very good model fit $(0.00 \leq \mathrm{RSR} \leq 0.50)$, good model fit $(0.50 \leq \mathrm{RSR} \leq 0.60)$, satisfactory model fit $(0.60 \leq \mathrm{RSR}$ $\leq 0.70$ ), and unsatisfactory model fit (RSR $>0.70$ ). However, these categories are based on simulations running on a monthly time-step. Moriasi et al. [39] noted that the acceptable range of RSR would increase in magnitude when using smaller time-steps, which was the case in this study. The MBE measures the average difference between sensor-estimated $\theta_{v}$ and $\theta_{r e f}$. A MBE of zero indicates the predicted and observed values are unbiased. A positive value of MBE means sensor is overestimating $\theta_{v}$, and negative MBE indicates underestimation [40]. The index of agreement $(k)$ was used to determine how well the sensor-estimated $\theta_{v}$ agreed with $\theta_{\text {ref }}$ [41]. The value of $k$ can range from zero to one, with one representing the highest level of agreement and zero representing complete disagreement [42].

In addition to the above statistical parameters, Pearson correlation coefficients $(r)$ were calculated for pairwise sensor comparisons to evaluate the similarity in their temporal variations throughout the study period. Closely correlated temporal patterns have a $r$ value near one, while this parameter is near zero in case of uncorrelated patterns [43]. Finally, linear regression models were fitted to sensor-estimated $\theta_{v}$ and $\theta_{\text {ref }}$ using the Minitab statistical software (version 17.3) (Minitab, Inc., State College, PA, USA) [44]. These linear models and the reported intercepts and slopes for each sensor can be used as field calibration equations in future applications at the study sites.

\section{Results and Discussion}

\subsection{Sensor Performance}

The fluctuations in $\theta_{v}$ were similar across all sensors at both study sites (Figure 2). All sensors responded to most irrigation and precipitation events. In some cases, there was little or no change in $\theta_{v}$ following a watering event, mainly because the amount of water received was not large enough to reach sensor installation depth. The results of performance evaluation (statistical indicators) are 
summarized in Table 3. In general, all sensors performed better at the LSLC. At this site, the RMSE was the lowest for CS655 $\left(0.019 \mathrm{~m}^{3} \mathrm{~m}^{-3}\right)$, followed by TDR315 $\left(0.028 \mathrm{~m}^{3} \mathrm{~m}^{-3}\right)$ and GS1 $\left(0.048 \mathrm{~m}^{3} \mathrm{~m}^{-3}\right)$. These values belong to the fair accuracy category defined in Fares et al. [20], suggesting that CS655, TDR315, and GS1 can be implemented for effective irrigation scheduling under conditions similar to those of LSLC. The RMSE values obtained in this study were smaller than the RMSE values of 0.105 and $0.049 \mathrm{~m}^{3} \mathrm{~m}^{-3}$ reported by Singh et al. [45] for the CS655 and TDR315 in a loam soil, respectively. Adeyemi et al. [46] found a similar RMSE of $0.020 \mathrm{~m}^{3} \mathrm{~m}^{-3}$ for TDR315 and $0.050 \mathrm{~m}^{3} \mathrm{~m}^{-3}$ for GS1 in a sandy loam soil under laboratory conditions. The RMSE of CropX was $0.051 \mathrm{~m}^{3} \mathrm{~m}^{-3}$, which is in the poor category. The SM100's RMSE was very poor $\left(0.110 \mathrm{~m}^{3} \mathrm{~m}^{-3}\right)$.

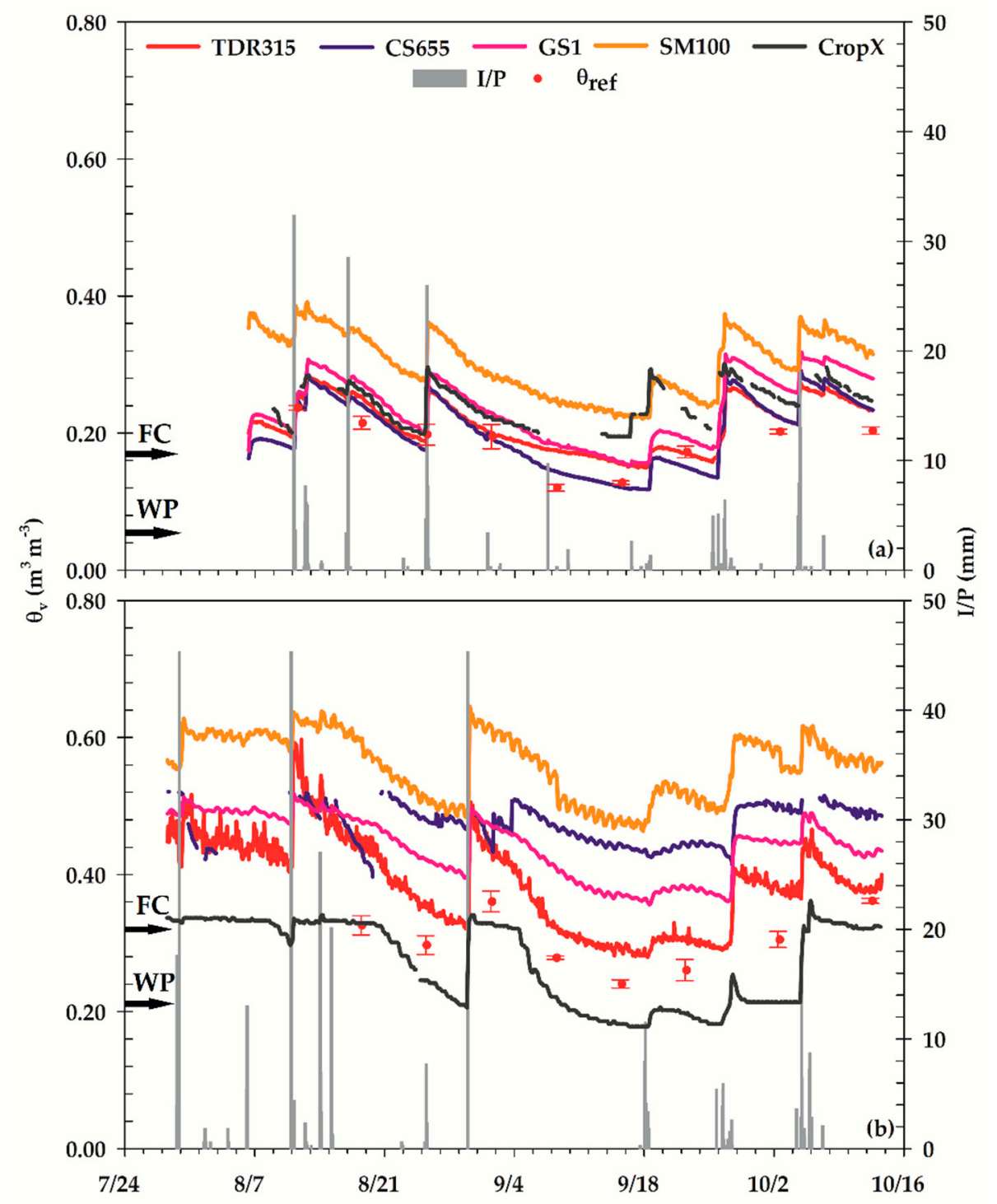

Figure 2. Time series of sensor-estimated $\theta_{v}$ along with point measurements of $\theta_{\text {ref }}$ at (a) lower salinity and lower clay content (LSLC) and (b) higher salinity and higher clay content (HSHC) sites. Error bars for $\theta_{\text {ref }}$ represent standard error of mean. The FC and WP limits were determined in the laboratory. 
Table 3. Performance indicators of soil moisture sensors.

\begin{tabular}{ccccccccccc}
\hline \multirow{2}{*}{ Indicators } & \multicolumn{2}{c}{ TDR315 } & \multicolumn{2}{c}{ CS655 } & \multicolumn{2}{c}{ GS1 } & \multicolumn{2}{c}{ SM100 } & \multicolumn{2}{c}{ CropX } \\
\cline { 2 - 11 } & LSLC & HSHC & LSLC & HSHC & LSLC & HSHC & LSLC & HSHC & LSLC & HSHC \\
\hline RMSE $\left(\mathrm{m}^{3} \mathrm{~m}^{-3}\right)$ & 0.028 & 0.064 & 0.019 & 0.165 & 0.048 & 0.122 & 0.110 & 0.233 & 0.051 & 0.055 \\
RSR & 0.76 & 1.55 & 0.53 & 3.99 & 1.31 & 2.97 & 3.00 & 5.66 & 2.53 & 1.34 \\
$\mathrm{MBE}\left(\mathrm{m}^{3} \mathrm{~m}^{-3}\right)$ & 0.020 & 0.053 & 0.008 & 0.160 & 0.042 & 0.121 & 0.108 & 0.233 & 0.045 & -0.049 \\
$\mathrm{k}$ & 0.85 & 0.69 & 0.94 & 0.30 & 0.69 & 0.41 & 0.44 & 0.26 & 0.58 & 0.75 \\
\hline
\end{tabular}

The MBE and RSR revealed similar patterns in sensor performance at the LSLC, with the CS655 performing the best, followed by TDR315, GS1, CropX, and SM100. The MBE indicated that all sensors overestimated $\theta_{v}$ at LSLC. This overestimation can also be observed in Figure 3 as most of the points were above the 1:1 line. Overestimation of $\theta_{v}$ by CS655 was observed by Kisekka et al. [47] and Michel et al. [48] too. Adeyemi et al. [46] found that TDR315 and GS1 underestimated $\theta_{v}$ in sandy loam soil, but, with increasing clay content, the underestimation became overestimation. The RSR ranged from 0.53 for CS655 to 3.00 for SM100 at LSLC site. According to categories defined by Moriasi et al. [39], the CS655 had a good model fit whereas all other sensors were classified as having unsatisfactory model fit. But as mentioned previously, running a model on temporal resolution higher than monthly would warrant less strict performance rating. Therefore, higher RSR values are expected in this study because of hourly time-step analysis. This trend was also observed in a study by Wyatt et al. [49], which produced high RSR values at daily time-step.

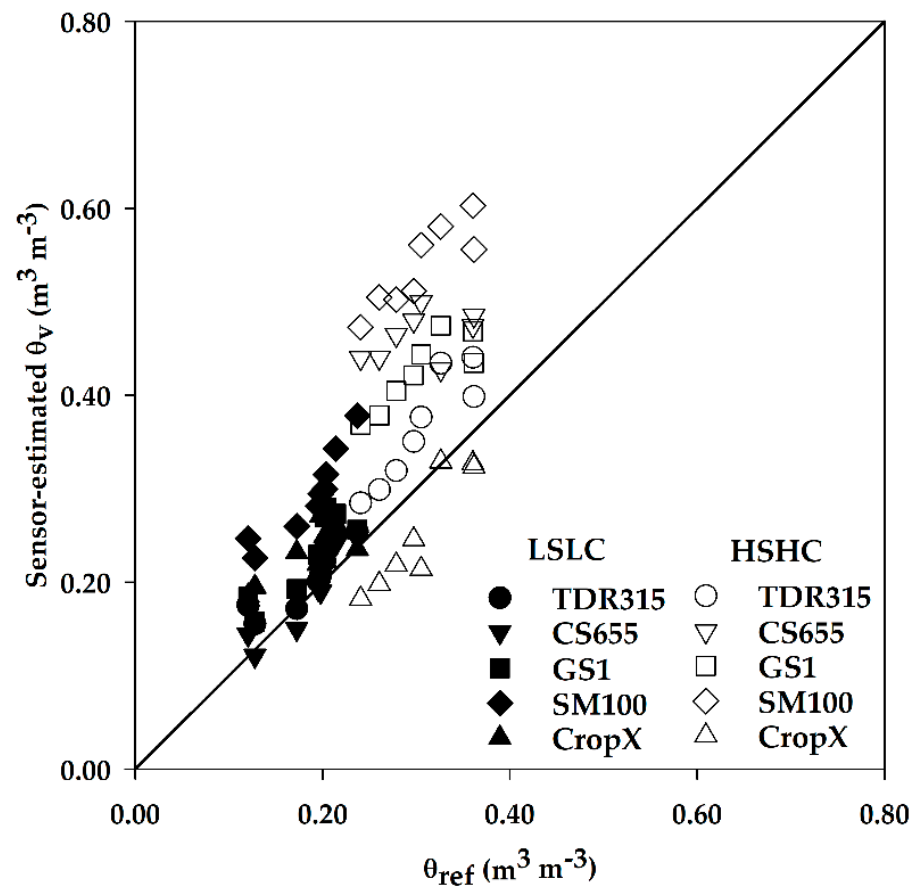

Figure 3. Sensor-estimated $\theta_{v}$ vs. $\theta_{\text {ref }}$ at LSLC and HSHC sites.

All sensors had larger RMSE at the HSHC site compared to LSLC (Table 3). However, the magnitude of the increase in RMSE was not uniform and changed from a slight increase for CropX to over an eight-fold increase for CS655. The CropX sensor had the smallest RMSE, followed by TDR315, GS1, CS655, and SM100. The values of RMSE belonged to the poor accuracy category in case of CropX and TDR315 and very poor category for other sensors according to classifications in Fares et al. [20], suggesting that none of the sensors can be implemented for effective irrigation scheduling under conditions similar to those of HSHC. In addition, the variability of readings among the replications of the same sensors increased at HSHC; the average standard deviation (SD) ranged from $0.021 \mathrm{~m}^{3} \mathrm{~m}^{-3}$ for TDR315 to $0.050 \mathrm{~m}^{3} \mathrm{~m}^{-3}$ for CS655. 
At LSLC, the average SD varied from $0.011 \mathrm{~m}^{3} \mathrm{~m}^{-3}$ for TDR315 to $0.023 \mathrm{~m}^{3} \mathrm{~m}^{-3}$ for GS1. The average SD of $\theta_{\text {ref }}$ was $0.015 \mathrm{~m}^{3} \mathrm{~m}^{-3}$ at LSLC and $0.010 \mathrm{~m}^{3} \mathrm{~m}^{-3}$ at HSHC.

High clay content and elevated levels of salinity seem to be the main reasons behind lower sensor accuracies at the HSHC site. Adeyemi et al. [46] concluded that the errors in TDR315 and GS1 would increase with an increase in soil salinity level. In addition, Wyseure et al. [16] reported that the error in TDR sensors would remain within reasonable limits if the bulk EC is kept less than $2 \mathrm{dS} \mathrm{m}^{-1}$. The bulk EC at HSHC, however, was well over this threshold. The MBE estimates were larger at HSHC than LSLC and showed that all sensors except CropX overestimated $\theta_{v}$. This is also evident in Figure 3. Most of previous studies have reported overestimation error for TDR sensors under saline conditions. This is mainly due to the fact that in saline soils, the dielectric permittivity measured by TDR increases and therefore $\theta_{v}$ is overestimated as mentioned in Dalton [15]. However, Schwartz et al. [18] found that TDR315 underestimated $\theta_{v}$ in a saline Pullman clay loam soil. The RSR values followed a pattern similar to other error indicators at HSHC, having the smallest value of 1.34 for CropX and the largest value of 5.66 for SM100.

Some noise in $\theta_{v}$ readings of the TDR315 at HSHC can be seen in Figure 2b. Schwartz et al. [18] reported that TDR315 sensors were insensitive to bulk EC up to $2.8 \mathrm{dS} \mathrm{m}^{-1}$ and corresponding pore water EC up to $7.3 \mathrm{dS} \mathrm{m}^{-1}$. The bulk EC and pore water EC exceeded these thresholds at HSHC on many days at the beginning of the study period. This might have caused signal attenuation that induced noise in $\theta_{v}$ readings. This noise was quantified using standard deviation (SD) in $\theta_{v}$ among the replications. At the beginning of the growing season, the SD had a range of zero to $0.099 \mathrm{~m}^{3} \mathrm{~m}^{-3}$ and an average of $0.021 \mathrm{~m}^{3} \mathrm{~m}^{-3}$ at HSHC for TDR315, which is much larger when compared to the range of 0.002 to $0.043 \mathrm{~m}^{3} \mathrm{~m}^{-3}$ and average of $0.012 \mathrm{~m}^{3} \mathrm{~m}^{-3}$ at LSLC during the same period. The observed noise was reduced later in the growing season, probably due to decrease in soil EC because of leaching of salts by irrigation water.

The hourly bulk EC estimates from TDR315 and CS655 were in agreement with soil EC determined in the laboratory and showed the significant difference between the two study sites (Figure 4). Both sensors reported small bulk EC at LSLC with similar ranges of 0.1 to $0.4 \mathrm{dS} \mathrm{m}^{-1}$. At HSHC, however, the bulk EC was significantly larger with ranges of 1.1 to 3.4 and 0.9 to $3.0 \mathrm{dS} \mathrm{m}^{-1}$ based on TDR315 and CS655 sensors, respectively.
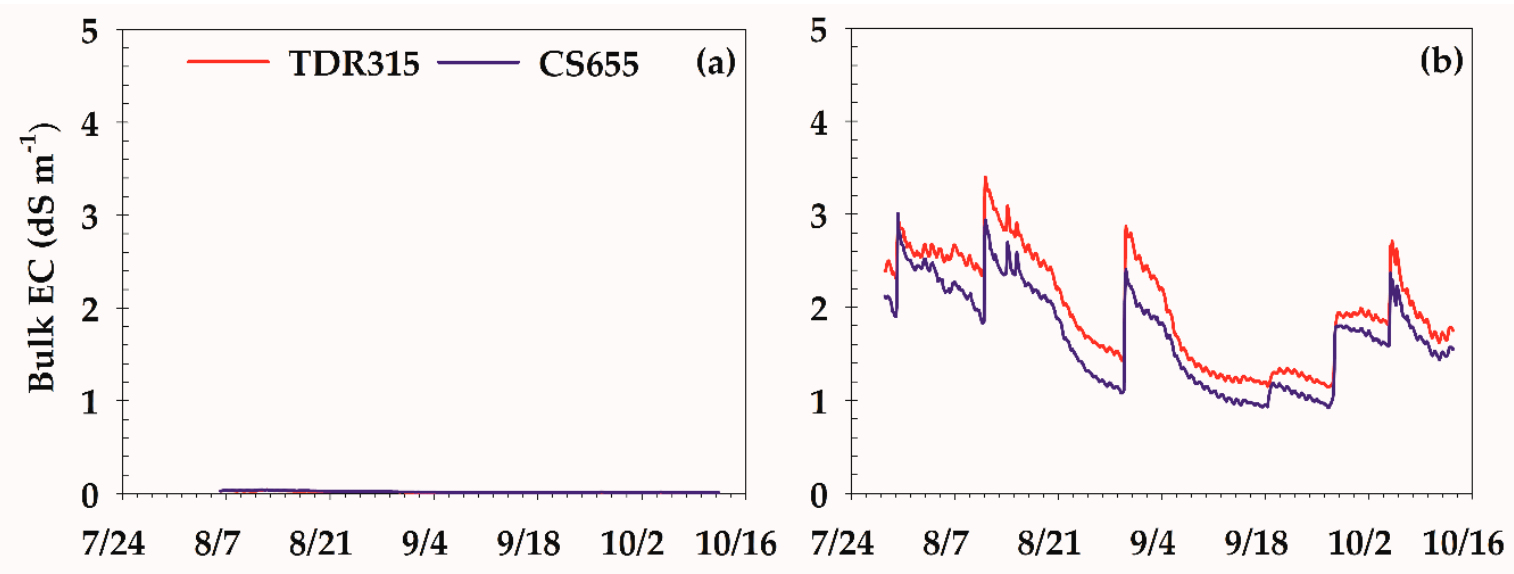

Figure 4. Time series of sensor-estimated Bulk electricity conductivity (EC) at (a) LSLC and (b) HSHC sites.

In utilizing soil moisture sensors for irrigation management, obtaining a complete time series is as important as taking accurate readings. In this study, CropX and CS655 had significant data gaps for different reasons. On average, $41 \%$ of the CropX data were missing at LSLC compared to less than one percent at HSHC. Several correspondences with the manufacturer revealed that the potential reason behind this issue could be the tall corn canopy at LSLC, which can block the transmitted signals. 
Upon recommendation from the manufacturer, extension antennas were installed on CropX sensors at LSLC. The observed crop height was $2.16 \mathrm{~m}$ and the extension antennas were installed in such a way that the tops of the antennae were $1.91 \mathrm{~m}$ from the ground. However, this modification did not help with the apparent transmission problem.

The CS655 had 21\% missing data at HSHC. Sugita et al. [50] conducted a reliability test on CS655 and found that the sensor was missing $64 \%$ of the measurements when exposed to high salinity levels (bulk EC $=1.2-2.1 \mathrm{dS} \mathrm{m}^{-1}$ ). The bulk EC at HSHC was larger than the values reported in Sugita et al. [50]. In addition to high salinity, the HSHC site had relatively high clay content (38.7\%). The clay particles have highly charged surface areas which increase dielectric losses and cause the apparent permittivity $\left(K_{a}\right)$ values to go outside the acceptable range of Topp equation [17]. The combined effect of higher soil salinity and clay content results in the attenuation of the electromagnetic signal from the sensor [18].Therefore, the sensor fails to report $\theta_{v}$ in case of $K_{a} \geq 42$ and $\theta_{v} \geq 0.52 \mathrm{~m}^{3} \mathrm{~m}^{-3}$ as the internal logical test rejects these data.

Linear regression equations were developed to estimate $\theta_{\text {ref }}$ based on sensor-estimated $\theta_{v}$ (Table 4). These equations can be used to get more accurate $\theta_{v}$ readings in areas matching this study's local conditions. At LSLC, the regression models were all statistically significant at $\alpha=0.05$, with $r^{2}$ values ranging from 0.57 for CropX to 0.85 for CS655. Although SM100 had low accuracy, the high $r^{2}$ value (0.84) indicates that this sensor had high degree of correlation with the reference values. At the HSHC site, the linear regression model for CS655 was not statistically significant. Models of other sensors were significant and had $r^{2}$ values varying from 0.73 to 0.85 .

Table 4. Parameters and the $p$-values of the linear regression equation: $\theta_{\text {ref }}=$ Slope $\times\left(\operatorname{sensor} \theta_{v}\right)$ + Intercept.

\begin{tabular}{cccccc}
\hline Site & Sensor & Intercept & Slope & $r^{2}$ & $p$-Value \\
\hline \multirow{4}{*}{ LSLC } & TDR315 & -0.017 & 0.975 & 0.80 & 0.001 \\
& CS655 & 0.036 & 0.771 & 0.85 & $<0.001$ \\
& GS1 & 0.017 & 0.737 & 0.70 & 0.005 \\
& SM100 & -0.033 & 0.747 & 0.84 & 0.001 \\
& CropX & -0.052 & 1.030 & 0.57 & 0.018 \\
\hline & TDR315 & 0.056 & 0.683 & 0.85 & 0.001 \\
& CS655 & -0.056 & 0.774 & 0.20 & $0.267^{\mathrm{T}}$ \\
HSHC & GS1 & -0.108 & 0.971 & 0.73 & 0.007 \\
& SM100 & -0.165 & 0.873 & 0.79 & 0.003 \\
& CropX & 0.137 & 0.656 & 0.85 & 0.001 \\
\hline
\end{tabular}

${ }^{\mathrm{T}}$ The linear regression model was not statistically significant.

\subsection{Correlations between Sensors}

In general, the Pearson's correlation coefficients $(r)$ of $\theta_{v}$ readings were larger at LSLC than HSHC (Table 5). At this site, the strongest correlation $(r=0.99)$ was between TDR315 and CS655 and the weakest was between CropX and SM100 $(r=0.79)$. The correlation coefficients for CropX were smallest among all sensors at the LSLC site, ranging from 0.79 to 0.81 . Despite being the least accurate sensor, SM100 had strong correlation with the top two accurate sensors, i.e., TDR315 and CS655. This indicates that SM100 closely followed the temporal changes in $\theta_{v}$ of more accurate sensors. At HSHC, the correlation between TDR315 and GS1 was the strongest ( $r=0.97)$. The SM100 also had strong correlations with TDR315, GS1, and CropX. On the other hand, CS655 had weak correlations with other sensors. 
Table 5. Pearson correlation coefficients among installed sensors at study sites.

\begin{tabular}{cccccc}
\hline \multicolumn{7}{c}{ LSLC } \\
\hline & TDR315 & CS655 & GS1 & SM100 & CropX \\
\hline TDR315 & 1.00 & & & & \\
CS655 & 0.99 & 1.00 & & & \\
GS1 & 0.97 & 0.99 & 1.00 & & \\
SM100 & 0.95 & 0.95 & 0.92 & 1.00 & \\
CropX & 0.79 & 0.81 & 0.81 & 0.79 & 1.00 \\
\hline \multicolumn{7}{c}{ HSHC } \\
\hline TDR315 & 1.00 & & & \\
CS655 & 0.50 & 1.00 & & & \\
GS1 & 0.97 & 0.57 & 1.00 & & \\
SM100 & 0.90 & 0.48 & 0.90 & 1.00 & \\
CropX & 0.86 & 0.42 & 0.85 & 0.78 & 1.00 \\
\hline
\end{tabular}

Note all correlation coefficients were significant at $p=0.05$.

The strong correlation between sensors with different accuracies suggests that the response of less accurate sensors to soil moisture fluctuations was similar to those of more accurate sensors. The differences in $\theta_{v}$ readings were relatively constant over the study period (offset error). This provides an opportunity for potential utilization of less accurate sensors in some limited applications where the user is only interested in determining the movement of the water front in the soil profile. One example of this application is leaching salts below the root zone. In this case, the user needs to ensure water front has moved below the bottom of the root zone. Another example is preventing deep percolation to ensure applied water remains within the root zone and that soluble chemicals are not transported to shallow groundwater resources.

\subsection{Soil Moisture Thresholds}

At LSLC, the FC and WP estimated in the laboratory were similar to the output of the Rosetta model based on textural class, textural information, and textural information plus bulk density (Table 6). Thresholds obtained from USDA's Web Soil Survey (USDA-WSS) were slightly larger than the results of the laboratory and Rosetta methods. However, the estimates based on the ranking of sensor readings were significantly larger than those of the other methods. The FC and WP values were larger at HSHC compared to LSLC irrespective of the method used because of larger clay content in the soils. The FC values from the Rosetta model and the USDA-WSS were either similar or slightly smaller than those obtained with the laboratory approach. All ranking estimates of FC were significantly larger than those with laboratory approach except for CropX, which was slightly larger. In the case of WP, estimates from the Rosetta model were significantly smaller than those with the laboratory approach, while USDA-WSS reported a similar value. Ranking method estimates were significantly larger except for CropX. The differences between AWC estimates of the ranking and laboratory methods were smaller than the differences in the FC and WP estimates of the same methods at both sites, mainly because overestimations in FC and WP estimates of the ranking method were of similar magnitudes and thus cancelled out to a large extent. 
Table 6. Estimates of field capacity (FC), wilting point (WP), and available water content (AWC) (all in $\mathrm{m}^{3} \mathrm{~m}^{-3}$ ) obtained from various methods.

\begin{tabular}{ccccccc}
\hline \multirow{2}{*}{ Method } & \multicolumn{3}{c}{ LSLC } & \multicolumn{3}{c}{ HSHC } \\
\cline { 2 - 7 } & FC & WP & AWC & FC & WP & AWC \\
\hline Laboratory $^{1}$ & 0.17 & 0.06 & 0.11 & 0.32 & 0.21 & 0.09 \\
Rank-TDR315 $^{2}$ & 0.27 & 0.16 & 0.11 & 0.49 & 0.29 & 0.20 \\
Rank-CS655 $^{2}$ & 0.27 & 0.12 & 0.15 & 0.51 & 0.43 & 0.08 \\
Rank-GS1 $^{2}$ & 0.31 & 0.16 & 0.15 & 0.50 & 0.37 & 0.13 \\
Rank-SM100 $^{2}$ & 0.37 & 0.23 & 0.14 & 0.62 & 0.48 & 0.14 \\
Rank-CropX $^{2}$ & 0.28 & 0.17 & 0.11 & 0.34 & 0.18 & 0.16 \\
Rosetta-TC $^{3}$ & 0.17 & 0.06 & 0.11 & 0.31 & 0.12 & 0.19 \\
Rosetta-TI $^{4}$ & 0.17 & 0.07 & 0.10 & 0.29 & 0.14 & 0.15 \\
Rosetta-TBD $^{5}$ & 0.15 & 0.07 & 0.08 & 0.26 & 0.14 & 0.12 \\
USDA-WSS $^{6}$ & 0.21 & 0.12 & 0.09 & 0.29 & 0.21 & 0.08 \\
\hline
\end{tabular}

${ }^{1}$ Laboratory measurement; ${ }^{2}$ Ranking method performed for each sensor; ${ }^{3}$ Rosetta model using soil textural class only; ${ }^{4}$ Rosetta model using soil textural information (\% sand, silt, and clay); ${ }^{5}$ Rosetta model using textural

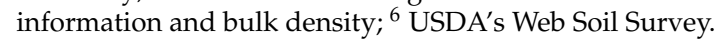

Results of this study reveal that the Rosetta model is capable of accurately estimating soil moisture thresholds even with minimal input data (textural classes). The USDA-WSS also performed satisfactorily, despite the fact that it is based on coarse soil surveys. However, the ranking method resulted in significant overestimation of FC when compared to laboratory estimates, ranging from 59 to $117 \%$ at the LSLC and from 6 to $94 \%$ at HSHC site. The difference between WP estimates of the ranking and laboratory methods varied from 100 to $283 \%$ at LSLC and from -14 to $129 \%$ at HSHC. A potential reason behind this poor performance could be that the full range of soil moisture conditions was not experienced at both sites during the period of study. However, this situation could be the case in many irrigated areas, since producers attempt to replenish soil moisture well before it reaches WP to avoid water stress and yield loss. Another reason behind the poor performance of the ranking method is the error in sensor readings, especially at HSHC, where most sensors overestimated soil moisture due to high clay content and elevated salinity levels.

Variations in hourly SMD are presented in Figure 5. In this figure, dots represent observed SMD based on $\theta_{\text {ref }}$ and laboratory-determined FC, while lines represent sensor SMD based on sensor $\theta_{v}$ and FC from two methods: laboratory and ranking. The Rosetta model was not considered here because the FC values obtained from the model were similar to those of the laboratory. At LSLC, observed SMD values were zero except on two sampling dates in early September. This is because this site was under full to slightly over-irrigation at most times during the study period. The only exception for the same period was in September when crop water demand outpaced irrigation application. Possible underestimation of $\theta_{F C}$ in the laboratory method may have contributed to zero SMD on most measurement dates too. In this study, a soil matric potential of $-33 \mathrm{kPa}$ was used to measure $\theta_{F C}$. But as mentioned before, this value can be as high as $-10 \mathrm{kPa}$ in sandy loam soil, resulting in a larger $\theta_{F C}$ and consequently a larger SMD estimate. Sensor SMDs based on laboratory-FC had similar patterns, indicating no depletion during the study period except in the month of September (Figure 5a). On the other hand, sensor SMDs based on ranking-FC showed significant depletions at most times, reaching values as large as $0.15 \mathrm{~m}^{3} \mathrm{~m}^{-3}$ (Figure $5 \mathrm{~b}$ ). This increase in SMD is mainly due to overestimation of FC in the ranking method, since the same sensors readings were used in both SMD approaches. 

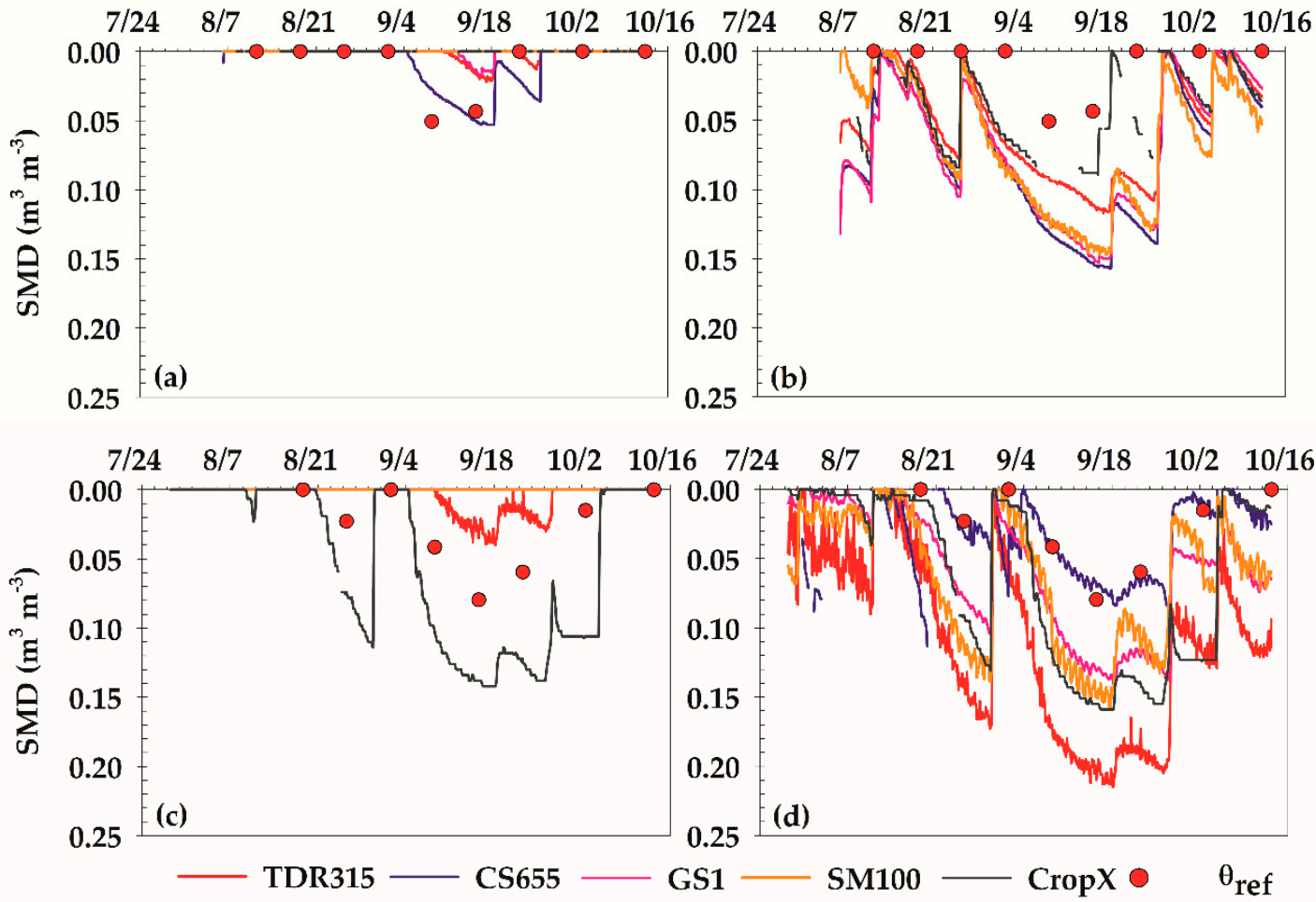

Figure 5. Time series of hourly soil moisture depletion (SMD) estimated based on sensor readings of $\theta_{v}$ and FC estimates from laboratory (a) and ranking (b) methods at LSLC site and laboratory (c) and ranking (d) methods at HSHC site. Dots represent SMD estimated based on $\theta_{\text {ref }}$ and FC estimates from laboratory method.

At the HSHC site, the observed SMD indicated a larger depletion, especially during early September to early October. This pattern was expected since this site was under a low-frequency (7-10 days) flood irrigation regime that was not able to meet cotton water demand during the hot and dry month of September. At this site, sensor SMDs based on laboratory-FC showed no depletion except for CropX and TDR315. The SMD estimates of CropX were larger and the SMD estimates of TDR315 were smaller than observed SMD. This is because CropX underestimated $\theta_{v}$, while TDR315 overestimated this parameter. The overestimation errors of the other sensors were so large that their $\theta_{v}$ readings were above laboratory-FC at all times, resulting in no depletion. The sensor SMDs based on ranking-FC were significantly larger than those based on laboratory-FC, except for CS655. This was because of the overestimation of FC by the ranking method. Hence, depletion was calculated at most times. The SMDs of CS655 were similar to the observed SMD, since the overestimation errors in $\theta_{v}$ readings and ranking-FC were similar in magnitude.

\section{Conclusions}

The performance of five types of commercially available soil moisture sensors was evaluated at two fields with significantly different salinity levels and clay contents. The sensors included TDR315, CS655, GS1, SM100, and CropX. The accuracy of each sensor was determined by comparing its readings with gravimetric measurements of soil water content obtained at several times during the study period. In general, all sensors responded to wetting and drying events. The TDR315, CS655, and GS1 sensors had acceptable accuracies for managing irrigations at the site with low salinity and low clay content (LSLC) based on root mean square error (RMSE). However, none of the sensors performed satisfactorily at the site with high salinity and high clay content (HSHC), with RMSE estimates that were up to eight times larger compared to the values at LSLC. In addition, high levels of noise were observed in TDR315 due to high salinity and out-of-range responses and consequently missing readings in case of CS655 sensor. A potential solution for using soil moisture sensors in irrigation scheduling under such conditions is the use of site-specific calibrations. 
For practical irrigation scheduling, sensor readings must be used in conjunction with soil moisture thresholds of field capacity (FC) and wilting point (WP) in order to estimate soil moisture depletion (SMD) and consequently irrigation requirement. In this study, FC and WP values determined in the laboratory using undisturbed soil cores were compared against those obtained from three independent approaches: the Rosetta model, the ranking of sensor readings, and the values reported in the U.S. Department of Agriculture's Web Soil Survey (USDA-WSS). The Rosetta model was capable of providing estimates similar to those of the laboratory approach, regardless of the type and number of input data used in the model. The USDA-WSS approach resulted in acceptable estimates of FC and WP. The ranking method, however, significantly overestimated FC and WP at both sites, even for accurate sensors. The ranking method did not perform well in estimating SMD either, except for one sensor at the HSHC site where the overestimation error in FC was similar to overestimation error in soil water content and canceled each other out. The results of this study show that two major conditions are required before the ranking method can be used effectively in estimating soil moisture thresholds: sensor readings that are the basis of calculations must be accurate; and, the full range of moisture conditions from below WP to above FC must be experienced during the data collection period.

This study contributes to the existing knowledge on sensor-based irrigation scheduling through quantifying the accuracies of five widely-used soil moisture sensors as impacted by soil clay content and salinity, as well as investigating the effectiveness of different soil moisture threshold estimation approaches for agricultural irrigation applications. The results highlight the wide range of accuracies that exist among soil moisture sensors and methods for determining soil moisture thresholds. Such a wide range creates major challenges in utilizing soil moisture sensors for irrigation scheduling applications. As new sensors are being developed frequently, studies like this need to be conducted under variable field conditions to evaluate the performance of the new sensors and to provide guidelines on how they can be used for irrigation scheduling purposes.

Author Contributions: S.D. conducted the study, collected and analyzed field data, and wrote the paper. S.T. conceived of this study, collected field data, and helped in analysis and writing the paper. T.E.O. helped in designing and planning the experimental setup of the study and provided valuable comments in writing and revising the paper. D.M., P.G., and J.L.S. were instrumental in acquiring instrumentation and helped in writing and revising the paper.

Funding: This manuscript is based upon work supported by the Natural Resources Conservation Service, U.S. Department of Agriculture, under No. 69-3A75-16-013. Additional funding was provided by the Agricultural Research Service, U.S. Department of Agriculture, under Agreement No. 58-3070-5-007 and by the U.S. Geological Survey 104 (b) program administered through the Oklahoma Water Resources Center.

Commercial Endorsement Disclaimer: The use of trade, corporation, and firm names in this article is for informational purpose only and is at convenience of the reader. Oklahoma State University and US Department of Agriculture neither approve nor endorse the use of products from these companies.

Conflicts of Interest: The authors declare no conflicts of interest.

\section{References}

1. United States Department of Agriculture (USDA). Farm and Ranch Irrigation Survey (2013); National Agricultural Statistics Service, Ed.; USDA: Washington, DC, USA, 2014; Volume 3, p. 266.

2. Maupin, M.A.; Kenny, J.F.; Hutson, S.S.; Lovelace, J.K.; Barber, N.L.; Linsey, K.S. Estimated Use of Water in the United States in 2010; US Geological Survey: Reston, VA, USA, 2014.

3. Fischer, G.; Tubiello, F.N.; Van Velthuizen, H.; Wiberg, D.A. Climate change impacts on irrigation water requirements: Effects of mitigation, 1990-2080. Technol. Forecast. Soc. Chang. 2007, 74, 1083-1107. [CrossRef]

4. Fishman, R.M. Climate Change, Rainfall Variability, and Adaptation through Irrigation: Evidence from Indian Agriculture. Unpublished work. 2012.

5. Datta, S.; Taghvaeian, S.; Stivers, J. Understanding Soil Water Content and Thresholds for Irrigation Management; Oklahoma Cooperative Extension Service: Stillwater, OK, USA, 2017.

6. Broner, I. Irrigation scheduling. In Service in Action; No. 4.708; Colorado State University Extension: Fort Collins, CO, USA, 2005. 
7. Martin, E. Methods of Measuring for Irrigation Scheduling-WHEN; Arizona Cooperative Extension: Tucson, AZ, USA, 2009.

8. Martin, E.C.; Pegelow, E.J.; Stedman, S. Comparison of Irrigation Scheduling Methods in Cotton Production; College of Agriculture, University of Arizona: Tucson, AZ, USA, 1995.

9. Fisher, D.K.; Hanks, J.E.; Pringle, H.L., III. Comparison of Irrigation Scheduling Methods in the Humid Mid-South. Irrigation Association. 2009. Available online: https://www.irrigation.org/IA/FileUploads/IA/ Resources/TechnicalPapers/2009/ComparisonOfIrrigationSchedulingMethodsInTheHumidMid-South. pdf (accessed on 21 August 2018).

10. Sui, R. Irrigation Scheduling Using Soil Moisture Sensors. J. Agric. Sci. 2017, 10, 1. [CrossRef]

11. Kebede, H.; Fisher, D.K.; Sui, R.; Reddy, K.N. Irrigation Methods and Scheduling in the Delta Region of Mississippi: Current Status and Strategies to Improve Irrigation Efficiency. Am. J. Plant Sci. 2014, 5, 50005. [CrossRef]

12. Zotarelli, L.; Scholberg, J.M.; Dukes, M.D.; Muñoz-Carpena, R.; Icerman, J. Tomato yield, biomass accumulation, root distribution and irrigation water use efficiency on a sandy soil, as affected by nitrogen rate and irrigation scheduling. Agric. Water Manag. 2009, 96, 23-34. [CrossRef]

13. Cardenas-Lailhacar, B.; Dukes, M. Precision of soil moisture sensor irrigation controllers under field conditions. Agric. Water Manag. 2010, 97, 666-672. [CrossRef]

14. Yoder, R.; Johnson, D.; Wilkerson, J.; Yoder, D. Soilwater sensor performance. Appl. Eng. Agric. 1998, 14, 121-133. [CrossRef]

15. Dalton, F. Development of time-domain reflectometry for measuring soil water content and bulk soil electrical conductivity. In Advances in Measurement of Soil Physical Properties: Bringing Theory into Practice; Topp, G.C., Daniel, W.D., Green, R.E., Eds.; Soil Science Society of America: Madison, WI, USA, 1992; pp. 143-167.

16. Wyseure, G.; Mojid, M.; Malik, M. Measurement of volumetric water content by TDR in saline soils. Eur. J. Soil Sci. 1997, 48, 347-354. [CrossRef]

17. Topp, G.C.; Davis, J.; Annan, A.P. Electromagnetic determination of soil water content: Measurements in coaxial transmission lines. Water Resour. Res. 1980, 16, 574-582. [CrossRef]

18. Schwartz, R.C.; Evett, S.R.; Anderson, S.K.; Anderson, D.J. Evaluation of a Direct-Coupled Time-Domain Reflectometry for Determination of Soil Water Content and Bulk Electrical Conductivity. Vadose Zone J. 2016, 15, 8. [CrossRef]

19. Rüdiger, C.; Western, A.W.; Walker, J.P.; Smith, A.B.; Kalma, J.D.; Willgoose, G.R. Towards a general equation for frequency domain reflectometers. J. Hydrol. 2010, 383, 319-329. [CrossRef]

20. Fares, A.; Abbas, F.; Maria, D.; Mair, A. Improved calibration functions of three capacitance probes for the measurement of soil moisture in tropical soils. Sensors 2011, 11, 4858-4874. [CrossRef] [PubMed]

21. Mittelbach, H.; Lehner, I.; Seneviratne, S.I. Comparison of four soil moisture sensor types under field conditions in Switzerland. J. Hydrol. 2012, 430, 39-49. [CrossRef]

22. Robinson, D.; Jones, S.B.; Wraith, J.; Or, D.; Friedman, S. A review of advances in dielectric and electrical conductivity measurement in soils using time domain reflectometry. Vadose Zone J. 2003, 2, 444-475. [CrossRef]

23. Chávez, J.L.; Varble, J.L.; Andales, A.A. Performance evaluation of selected soil moisture sensors. In Proceedings of the 23rd Central Plains Irrigation Conference, Burlington, CO, USA, 22-23 February 2011; pp. 29-38.

24. Environment, M. GS1: Soil Moisture Sensor Operations Manual; METER Group, Inc.: Pullman, WA, USA, 2015; p. 22.

25. Daly, C.; Halbleib, M.; Smith, J.I.; Gibson, W.P.; Doggett, M.K.; Taylor, G.H.; Curtis, J.; Pasteris, P.P. Physiographically sensitive mapping of climatological temperature and precipitation across the conterminous United States. Int. J. Climatol. 2008, 28, 2031-2064. [CrossRef]

26. Leib, B.G.; Jabro, J.D.; Matthews, G.R. Field evaluation and performance comparison of soil moisture sensors. Soil Sci. 2003, 168, 396-408. [CrossRef]

27. Brutsaert, W. Daily evaporation from drying soil: Universal parameterization with similarity. Water Resour. Res. 2014, 50, 3206-3215. [CrossRef]

28. Ashworth, J.; Keyes, D.; Kirk, R.; Lessard, R. Standard procedure in the hydrometer method for particle size analysis. Commun. Soil Sci. Plant Anal. 2001, 32, 633-642. [CrossRef] 
29. Zhang, H.; Kress, M.F.; Johnson, G.V. Procedures Used by OSU Soil, Water, and Forage Analytical Laboratory; Division of Agricultural Sciences and Natural Resources, Oklahoma State University: Stillwater, OK, USA, 2002.

30. Aguilar, J.; Rogers, D.; Kisekka, I. Irrigation Scheduling Based on Soil Moisture Sensors and Evapotranspiration. Kansas Agric. Exp. Stn. Res. Rep. 2015, 1, 20. [CrossRef]

31. McPherson, R.A.; Fiebrich, C.A.; Crawford, K.C.; Kilby, J.R.; Grimsley, D.L.; Martinez, J.E.; Basara, J.B.; Illston, B.G.; Morris, D.A.; Kloesel, K.A. Statewide monitoring of the mesoscale environment: A technical update on the Oklahoma Mesonet. J. Atmos. Ocean. Technol. 2007, 24, 301-321. [CrossRef]

32. Van Lier, Q.d.J. Field capacity, a valid upper limit of crop available water? Agric. Water Manag. 2017, 193, 214-220. [CrossRef]

33. Tolk, J.A. Soils, Permanent Wilting Points. In Encyclopedia of Water Science; Taylor \& Francis: New York, NY, USA, 2003.

34. Schaap, M.G.; Leij, F.J.; Van Genuchten, M.T. Rosetta: A computer program for estimating soil hydraulic parameters with hierarchical pedotransfer functions. J. Hydrol. 2001, 251, 163-176. [CrossRef]

35. Dane, J.H.; Hopmans, J.W. Water retention and storage-Introduction. In Methods of Soil Analysis Part 4; Dane, J.H., Topp, G.C., Eds.; Soil Science Society of America: Madison, WI, USA, 2002; pp. 671-717.

36. Hunt, E.D.; Hubbard, K.G.; Wilhite, D.A.; Arkebauer, T.J.; Dutcher, A.L. The development and evaluation of a soil moisture index. Int. J. Climatol. 2009, 29, 747-759. [CrossRef]

37. NRCS. Web Soil Survey. 2009. Available online: http://www.websoilsurvey.ncsc.usda.gov/app/ (accessed on 29 October 2017).

38. Cassel, D.; Nielsen, D. Field Capacity and Available Water Capacity. In Methods of Soil Analysis Part 1; Klute, A., Ed.; Soil Science Society of America: Madison, WI, USA, 1986; pp. 901-926.

39. Moriasi, D.N.; Arnold, J.G.; Van Liew, M.W.; Bingner, R.L.; Harmel, R.D.; Veith, T.L. Model evaluation guidelines for systematic quantification of accuracy in watershed simulations. Trans. ASABE 2007, 50, 885-900. [CrossRef]

40. Addiscott, T.; Whitmore, A. Computer simulation of changes in soil mineral nitrogen and crop nitrogen during autumn, winter and spring. J. Agric. Sci. 1987, 109, 141-157. [CrossRef]

41. Willmott, C.J. On the validation of models. Phys. Geogr. 1981, 2, 184-194. [CrossRef]

42. Mishra, A.; Vu, T.; Veettil, A.V.; Entekhabi, D. Drought monitoring with soil moisture active passive (SMAP) measurements. J. Hydrol. 2017, 552, 620-632. [CrossRef]

43. Cosh, M.H.; Jackson, T.J.; Bindlish, R.; Prueger, J.H. Watershed scale temporal and spatial stability of soil moisture and its role in validating satellite estimates. Remote Sens. Environ. 2004, 92, 427-435. [CrossRef]

44. Montgomery, D.C.; Peck, E.A.; Vining, G.G. Introduction to Linear Regression Analysis; John Wiley \& Sons: Hoboken, NJ, USA, 2012; Volume 821.

45. Singh, J.; Lo, T.; Rudnick, D.R.; Dorr, T.J.; Burr, C.A.; Werle, R.; Shaver, T.M.; Muñoz-Arriola, F. Performance assessment of factory and field calibrations for electromagnetic sensors in a loam soil. Agric. Water Manag. 2018, 196, 87-98. [CrossRef]

46. Adeyemi, O.; Norton, T.; Grove, I.; Peets, S. Performance evaluation of three newly developed soil moisture sensors. In Proceedings of the CIGR-AgEng Conference, Aarhus, Denmark, 26-29 June 2016; pp. 26-29.

47. Kisekka, I.; Aguilar, J.; Lamm, F.; Rogers, D. Using Soil Water and Canopy Temperature to Improve Irrigation Scheduling for Corn. In Proceedings of the 2014 Irrigation Association Conference, Phoenix, AZ, USA, 3-6 November 2014.

48. Michel, A.; Brown, H.; Gillespie, R.; George, M.; Meenken, E. Automated measurement of crop water balances under a mobile rain-exclusion facility. Agron. N. Z. 2015, 45, 39-46.

49. Wyatt, B.M.; Ochsner, T.E.; Fiebrich, C.A.; Neel, C.R.; Wallace, D.S. Useful Drainage Estimates Obtained from a Large-Scale Soil Moisture Monitoring Network by Applying the Unit-Gradient Assumption. Vadose Zone J. 2017, 16, 16. [CrossRef]

50. Sugita, M.; Kubota, A.; Higuchi, M.; Matsuno, A.; Tanaka, H. Continuous soil moisture monitoring under high salinity conditions by dielectric sensors: A reliability test. Tsukuba Geoenviron. Sci. 2016, 12, 17-22.

(C) 2018 by the authors. Licensee MDPI, Basel, Switzerland. This article is an open access article distributed under the terms and conditions of the Creative Commons Attribution (CC BY) license (http:/ / creativecommons.org/licenses/by/4.0/). 